\title{
artículos
}

\section{A vueltas con el dolor y el cuerpo: la performance contemporánea de Ron Athey}

\author{
Ana María Sedeño Valdellós \\ Universidad de Málaga
}

RESUMEN

El performer norteamericano Ron Athey experimenta en su trabajo con los límites del dolor corporal en relación con toda una iconografia y tradición religiosa. Esta combinación de ideas ya había sido empleada anteriormente, en alguna de sus componentes, por otros autores pertenecientes a grupos como el accionismo vienés, pero también por Gina Pane, Marina Abramovic, Chris Burden o Franko B. El cuerpo, soporte de la práctica artística y, en este caso, del dolor, es la vía de comunicación con el público, medio para organizar acciones de tendencia ritual y contrasexual, que esconden una fuerte crítica al orden dominante del arte y la sociedad.

PALABRAS CLAVE: Ron Athey/ Performance/ Arte contemporáneo/ Dolor en el arte/ Cuerpo en el arte.

Around Pain and Body: Ron Athey's contemporary performance

ABSTRACT

The North American performer Ron Athey experiments on his work with the limits of the corporal pain on relation with the whole iconography and religious tradition. This combination of ideas had already been used previously, in someone of its components, by other authors belonging to groups as the Viennese Actionism, but also by Gina Pane, Marina Abramovic, Chris Burden o Franko B. The body, support of the artistic practice and, in this case, of the pain, is the link with the audience, way to organize actions of ritual and countersexual trends, which hide a strong critique to the order in art and society.

KEY WORDS: Ron Athey/ Performance/Comtemporary art/ Body pain/ Body art.

El cuerpo es uno de los componentes artísticos más destacados del arte contemporáneo desde los años sesenta. El performance y el body art surgieron como formas con las que se nombraban diferentes modalidades de empleo del cuerpo como material artístico. El performer norteamericano Ron Athey apuesta en su trabajo por obras que tienden a la radicalidad en su búsqueda del límite de dolor corporal, fórmula expiatoria de un moral sufrimiento interior.

La práctica artística de Ron Athey se basa en dos pilares primigenios que lo entroncan con toda una tradición artística anterior, desde el accionismo vienés y la performance norteamericana de los años sesenta hasta creadores actuales. Por un lado, la performance como disciplina donde encuadrarse y, por otro, la recuperación del rito y su como práctica social en el que el artista es una especie de intermediario o chamán al servicio de la audiencia.

* SEDEÑO VALDELLÓS, Ana María: "A vueltas con el dolor y el cuerpo: la performance contemporánea de Ron Athe", en Boletín de Arte, n 30-31, Departamento de Historia del Arte, Universidad de Málaga, 20092010, págs. 511-518. Fecha de entrega: Mayo de 2009. 


\section{El CUERPo: LA PERFORMANCE COMO PRÁCTICA ARTISTICA.}

Se denomina performance al arte de acción que se populariza en los años setenta desde el ámbito anglosajón, reemplazando a acción para describir realizaciones artísticas públicas, aunque sin necesaria participación de espectadores. Tiene que ver con ciertos aspectos de la situación teatral, aunque reivindicando una mayor presencia del cuerpo como agente del conocimiento, la danza, lo visual, ciertos comportamientos sociales y el acontecimiento como gesto límite de la vida.

"El cuerpo soporte del discurso, duración en un tiempo limitado y acción, mostrados o expuestos en una presencia real y efímera o documental podrían ser principios que definan la performance, tanto si es el lenguaje explícito de la obra como si tan sólo es uno de sus elementos"1

Por otro lado está la audiencia. Una obra artística en permanente proceso, como se definen las prácticas de performance, reclama un espectador activo que lleve a cabo una recepción no clásica:

"El artista no es el único que consuma el acto creador, pues el espectador establece el contacto de la obra con el mundo exterior, descifrando e interpretando sus profundas calificaciones para añadir entonces su propia contribución al proceso creativo"2.

La performance es esa práctica donde el artista está autorizado a convertirse en autor o creador y objeto de arte a la vez: su materialización se encuentra en el cuerpo, santuario donde tiene lugar esa fisión.

"Yo soy el agente de una acción y, al mismo tiempo, el receptor de la acción; 'yo' inicio una acción que termina en "mí"3.

La danza y algunos de sus creadores de los años sesenta estrenaron este interés por la relación del espacio y el cuerpo en la performance: la Danza Nueva, el Dancer's Workshops Company de San Francisco y la Judson Dance Group de Nueva York observaron el cuerpo como objeto desde el que realizar acciones de todo tipo, sacadas de sus contextos comunes e introducidas en una coreografía, aspecto básico de la danza contemporánea.

Más tarde, alejados de la performance danzable, otros artistas toman su cuer-

1 TORRES, D. G.: "La vigencia oculta de la performance" en Lápiz, Revista Internacional de Arte, no 132, Madrid, 1997.

2 DUCHAMP, M.: "El proceso creativo" en Escritos. Duchamp du Signe, Gili Gaya, Barcelona, 1975, pág. 163.

3 ACCONCI, V.: "En torno a la acción" en Fin del arte. Teorías. Conceptos. Testimonios. (http://artecontempo.blogspot.com/2005/10/vito-acconci.html, Fecha de consulta: 7 de enero de 2009) 


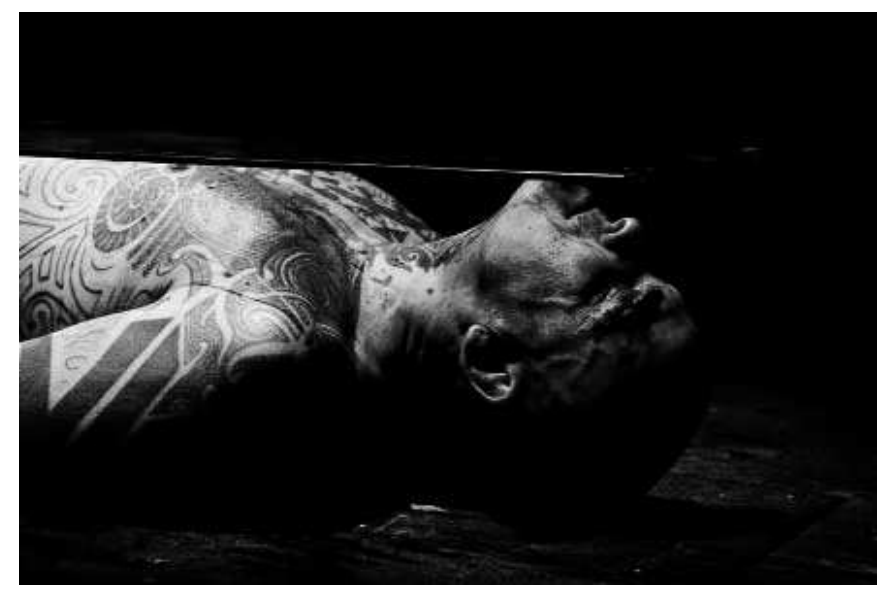

1. Chintoglass.

po como punto de partida, ya sea para interpretar su identidad, ya para denunciar diferentes tipos de maltrato social, político, psíquico o de género. El accionismo vienés se encuentra entre los grupos más sólidos y reconocidos.

Hermann Nitsch realizó obras como una manera estética de orar y desarrolló su concepto Orgen Mysterien Theater (Teatro de Orgías y Misterios), una serie de acciones colectivas durante los años setenta, de exploración del ritualismo antiguo, que incluían con frecuencia sacrificios animales. El ruido se convirtió en una parte importante de los eventos, pues tenían una función separadora de sus límites.

Para Otto Mühl, la performance ritual influida por la psicología fue una forma de arte y una actitud existencial. En relación con esta tendencia psicologista se encuentran Günter Brusy Arnulf Rainer. El primero de ellos utilizó su cuerpo en prácticas sadomasoquistas relacionadas con pulsiones sexuales y represiones freudianas. Arnulf Rainer basó su trabajo sobre el mismo concepto en su descripción de dementes.

Los desnudos artísticos de Rudolf Schwartzkogler, basados en automutilaciones, lo condujeron a la muerte en 1969.

Stuart Brisley destaca por su trabajo en body art, donde rechaza los valores capitalistas que oprimen al ser humano en sus dimensiones individual y social. En $Y$ para hoy, nada permaneció dos semanas, a intervalos de dos horas cada día, en una bañera con líquido negro y escombros flotando.

Gina Pane comparte la visión purificadora del ritual de Nitsch. En su obra El condicionante se colocaba tumbada en una cama sin apenas travesaños, debajo de las que ardían quince velas.

Reinder Werk pareja de jóvenes artistas londinenses se preocuparon por los 
marginados sociales y recrearon su gestualidad en Tierra del comportamiento en el Butler's Wharf de Londres (1977).

En sus serie de Ritmos (10, 5, 2, 0), Marina Abramovic ha explorado el dolor y ha probado su resistencia física a su acción, de manera autoinfligida o por otros. Con frecuencia, sus performances se desarrollaban y/o han concluido inesperadamente debido a accidentes e imprevistos, que han llegado a poner su vida en peligro.

En Ritmo 10 (1973), su primera performance (que puede considerarse videoperformance, por el destacado papel de la grabación visual más allá de la documentación) se autocorta mediante cuchillos sucesivos con movimientos repetitivos entre los dedos. Tras llegar al cuchillo número veinte, reproduce las imágenes e intenta imitar sus gestos para conseguir idénticos resultados.

Ritmo 5 (1974) procede a un ritual curativo cortando sus uñas y pelo y quemándolos en un fuego purificador. Tras ello, salta al centro de las llamas y cae inconsciente. El público la salva finalmente.

En Ritmo 2 (1974) juega con los estados de inconsciencia extremos a través de la ingesta de pastillas, con los que experimenta con la relación entre cuerpo y mente.

En Ritmo O (1974) permitió ser maltratada por una sala llena de espectadores. La performance terminó antes de lo previsto con una pistola en la sien de la Performer y una lucha entre participantes.

La presencia del cuerpo se encuentra también en la base de la acción conjunta Imponderabilia, que consistía en obligar al espectador a pasar al supuesto recinto de la performance a través de un espacio muy pequeño entre dos cuerpos desnudos, el suyo propio y el de su colaborador Ulay.

En Estados Unidos, las performances basadas en estos componentes carecen de esta radicalidad. Joan Jonas explora las ceremonias de tribus de indios norteamericanos. En Demora Demora (1972), se utilizaban las azoteas y los desvanes de edificios altos de la ciudad desde los que se realiza la performance, mientras los espectadores quedaban abajo; el sonido se convertía en nexo de unión entre alturas. Embudo (1974) o Telepatía visual de la miel orgánica (1972) son algunas obras más.

Se reconoce en Chris Burden al artista que se ha acercado más al peligro en escenificaciones performances, como en Shoot, Five Day Locker Piece (1971), Deadman (1972), B.C. Mexico (1973), Fire Roll (1973), TV Hijack (1978) y Honest Labor (1979, en las que se ha disparado, crucificado, encerrado durante días en espacios pequeños...

Más cercano en el tiempo, Franko B es un artista multimedia centrado en la representación de lo visceral de su propia sangre como medio para encontrar el dolor. Es un máximo exponente del live art y el teatro de la crueldad en nuestros días. 


\section{EL DOLOR CORPORAL COMO CATARSIS EN LA PRACTICA ARTISTICA} DE Ron Athey.

La base simbólica de la performance de estos artistas desde el accionismo vienés se sustenta en el rito y su capacidad de transmisión en situaciones comunales, así como en la fiesta.

El rito, como lugar donde se ejecutan acciones que sobrepasan lo permitido o legítimo en una sociedad, posee un componente liberador o catárquico, con una gran capacidad de contagio por empatía en situaciones sociales. Como en el rito el performer emplea su cuerpo como medio donde confluyen las fuerzas de la naturaleza y la vida humana. El receptor de estas acciones se sitúa como testigo colectivo, parte necesaria para la catarsis ritual.

Por otro lado, se encuentran las prácticas de sacrificio, con un componente de crítica social. Si el sufrimiento es consecuencia del dolor, en este caso se invierten los términos: el sufrimiento, "significado afectivo que traduzca el desplazamiento de un fenómeno fisiológico al centro de la conciencia moral del individuo"4, lleva al performer a buscar la herida y el dolor físicos como medios hacia un estado alterado con el que alcanzar ese nivel ritual. En este proceso puede hallarse la añoranza de los mártires y místicos cristianos: la búsqueda del conocimiento y la fusión con el más allá a través del dolor.

El artista trata de explicitar la carencia de trascendencia de la sociedad actual, para lo que se convierte en intermediario. Su cuerpo es soporte y medio para ese salto a estadios primitivos de la vida humana, donde cabían fórmulas de fusión con la divinidad:

"el ritual era evocado como parte de un inconsciente colectivo que hundía sus raíces en un comportamiento animal ligado a nuestras funciones básicas. Su práctica en el seno de la sociedad moderna pretendía ser una reactualización del tronco común sobre el cual todas las culturas han escenificado sus rituales" 5 .

En relación con la performance, el body art recurre a materiales artísticos alejados de los tradicionales, como los producidos por el cuerpo del artista: pelos, uñas, orina, heces y semen, entre otros, y a la modificación de las superficies corporales como pieza integrante de la obra. La piel del performer, superficie o borde del cuerpo entendido como soporte, deviene en lienzo para la obra, aunque algunos artistas traspasan esa barrera para explorar su interioridad a través de sus orificios, algo que describe al llamado disturbation art. Vagina, pene, ano, boca... hacen imaginar fórmulas para su exhibición, para traer fuera lo que se produce en el interior, en senti-

4 HERNÁNDEZ NAVARRO, M. Á.: "En torno al dolor en el body art". (Tit. or.: "Re-Presenting Pain in Body Art”), en SCIENCE MUSEUM: Pain, Passion. Compassion. Sensibility., Londres, 2004.

http://www.teleskop.es/hemeroteca/numero5/arte/art02.html (Fecha de consulta: 15 de diciembre de 2008). 5 TORRES, op. cit. 


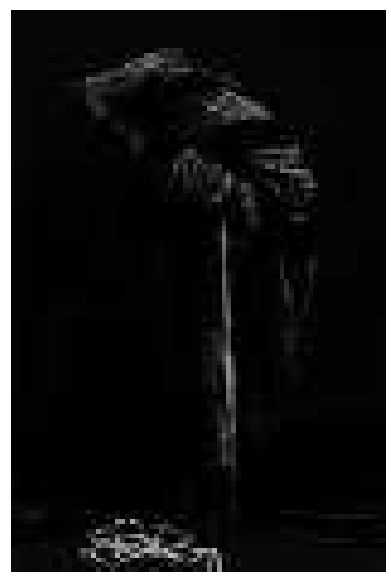

2. Cathie Opie's.

do literal y metafórico: piercings, tatuajes, perforaciones, quemaduras y demás marcas y autolesiones son separadas de su contexto negativo para sacralizarlas o introducirlas en acciones globales de diferente carácter.

"Nuestra identidad body/corpo/arte-facto debe ser marcada, decorada, pintada, vestida, culturalmente intervenida, re-politizada, trazada como un mapa, relatada, y finalmente documentada. Cuando nuestro cuerpo está herido o enfermo, inevitablemente nuestro trabajo cambia."6

Quizás sea Ron Athey, artista norteamericano quien resume mejor todas estas aspiraciones artísticas. Sus influencias incluyen desde las literarias (Jean Genet y Georges Bataille) hasta las relacionadas con la teoría queer de la representación y revisión del acto y la identidad sexual. El artista adopta roles sagrados con los que pretende iniciar a la audiencia en un viaje hacia tradiciones sagradas donde introduce problemáticas contemporáneas como el sida y la homosexualidad, junto a su discriminación consecuente. Lo que disturba de sus trabajos es el enlace real entre las emociones religiosas (especialmente cristianas) y su iconografía del dolor y la pulsión erótica, que se sublima en el éxtasis.

Su formación en el campo de la performance comienza en 1981 con Premature Ejaculation con Rozz Williams, líder del grupo Christian Death. La trilogía de la tortura (comenzada en 1992) resulta un paradigma de su posterior relación con los temas eternos de la enfermedad y la muerte y está compuesta por Martyrs and Saints, 4 scenes in a harsh life y Deliverance.

En Martyrs and Saints tres enfermeras violan con enemas, espéculos y varios

6 GÓMEZ PEÑA, G.: "En defensa del arte del performance" en Horizontes Antropológicos, Porto Alegre, año $11, n^{\circ} 24$, págs. 199-226, jul./dec. 2005, pág. 205. 
piercings genitales a tres cuerpos momificados.

En Four Scenes from a Harsh life (1993) emplea la iconografía homosexual del San Sebastián, con toda su piel saeteada y heridas supurantes. En ella, Athey interpreta a una mujer santa y termina protagonizando una escena de suicidio insertando sobre su brazo dieciséis agujas hipodérmicas.

En Deliverance (1997) las imágenes procedentes de ritos de la santería, el catolicismo, el budismo o el judaísmo se combinan en igualdad, camino a un sadismo santificado por el éxtasis. La obra examina el fenómeno filipino de la curación por la fe a través de la cirugía psíquica. Tres hombres con muletas van a visitar al curandero y terminan sangrando suspendidos sobre ganchos de carne, castrados para ser momificados y finalmente enterrados.

Joyce se estrenó en el prestigioso Kampnagel Theater de Hamburgo (Alemania) en febrero de 2002 y es una presentación teatral multimedia, cuya premisa resume las creencias insanas y los comportamientos escandalosos de la perversidad religiosa de su familia. Tres inmensas pantallas proyectan imágenes del joven Athey mutilándose, además de otras representaciones de su vida familiar.

El body art y el performance explotan la problemática de género y la del activismo gay con aspiraciones de agitación y protesta. Es el caso de la llamada contrasexualidad, definida por Judith Butler como "un análisis crítico de la diferencia de género y sexo, producto del contrato social, heterocentrado, cuyas performatividades normativas han sido inscritas en los cuerpos como verdades biológicas"7. Solar Anus (El ano solar) o Fuckhead (2002) son buenos ejemplos de ella. La primera de ellas se refiere directamente a un ensayo de George Bataille y se encuentra en consonancia con las propuestas de filósofos queer u otros autores admirados como Pier Paolo Pasolini.

Otras performances más recientes son Judas Cradle, un duo operístico en colaboración con la soprano Juliana Snapper y el diseñador de sonido Sean Griffin, Flash: Dissociative Sparkle (representada en la Nacional Review of Live Art en Glasgow y en Artists Space en Nueva York) y Pleading in the blood (2001), sobre la sodomía. El trabajo de Ron Athey está basado en trascender los límites del dolor físico y manifiesta un intento no sólo de exorcizar su dolor sino el de traspasar los límites de su resistencia a través de la expresión artística. Con ello, parecería querer demostrar que sólo a través de la catarsis de la performance y el ritual es posible escapar de los obstáculos que imponen el género, la familia, la religión y la sociedad al ser humano.

"If the inside of your head gets pummeled with enough emotional blunt force trauma to splinter the psyche, you develop ways to punish the body, that fleshy prison which houses the pain" 8 .

\footnotetext{
7 PRECIADO, B.: Manifiesto contrasexual: Prácticas subversivas de identidad sexual, Editorial Ópera Prima: Pensamiento, Madrid, 2002.

8 " Si aporrean el interior de tu cabeza con suficientes traumas como para embotarla y astillar tu psique, desarrolla modos de castigar el cuerpo, la prisión que contiene ese dolor ". Palabras de Ron Athey en su web wwww.ronathey.com (Traducción propia). * SEDEÑO VALDELLÓS, Ana María: en Boletín de Arte, $\mathrm{n}^{\circ} 30$, Departamento de Historia del Arte, Universidad de Málaga, 2009, págs.
} 


\section{Orientación Bibliográfica.}

-ACCONCI, V.: "En torno a la acción" en Fin del arte. Teorías. Conceptos. Testimonios. (http://artecontempo.blogspot.com/2005/10/vito-acconci.html, Fecha de consulta: 7 de enero de 2009).

-AZNAR ALMAZÁN, S.: El arte de acción, Nerea, Guipúzcoa, 2000.

-CASTRO, F.: "Fluxus: la subversión de lo cotidiano" en Panorama del arte contemporáneo, 1960-1990, Caja de Asturias, Oviedo, 1995, pp. 131-155.

-Estudios sobre performance, Centro Andaluz de Teatro, Sevilla, 1993.

-DUCHAMP, M.: "El proceso creativo" en Escritos. Duchamp du Signe, Gili Gaya, Barcelona, 1975.

-GOLDBERG, R.: Performance Art, Destino, Barcelona, 1996.

-GÓMEZ PEÑA, G.: "En defensa del arte del performance" en Horizontes Antropológicos, Porto Alegre, año 11, n 24, p. 199-226, jul./dec. 2005.

-GUALDONI, F.: Art: Todos los movimientos del siglo xx desde el Postimpresionismo hasta los New Media, Skira, Milán, 2008.

-GUASCH, A.M.: El arte del siglo XX en sus exposiciones. 1945-1995,

Ediciones del Serbal, Barcelona, 1997.

-HERNÁNDEZ NAVARRO, M. Á.: "En torno al dolor en el body art'. (Tit. or.:

"Re-Presenting Pain in Body Art"), en SCIENCE MUSEUM. Pain, Passion. Compassion. Sensibility, Londres, 2004.

http://www.teleskop.es/hemeroteca/numero5/arte/art02.html (Fecha de consulta: 15 de diciembre de 2008)

-LEBEL, J.J.: Le happening, Denoël, Paris, 1966.

-LUCIE-SMITH, E.: Movimientos artísticos desde 1945, Destino, Barcelona, 1993.

-MARCHÁN FIZ, S.: Del arte objetual al arte del concepto, Akal, Madrid, 1986. -PRECIADO, B.: Manifiesto contrasexual: Prácticas subversivas de identidad sexual, Editorial Ópera Prima: Pensamiento, Madrid, 2002.

-RODRÍGUEZ BIDONDO, A. (ed.): "Body Art" en El Mundo entre Paréntesis, Etapa III, Año 3, n 4, agosto 2003, Cuba. http://www.cip.cu/sic/2003/03/index.html

-TORRES, D. G.: "La vigencia oculta de la performance" en Lápiz, Revista Internacional de Arte, $\mathrm{n}^{\circ}$ 132, Madrid, 1997.

-www.ronathey.com 